\title{
ENTERPRISE NETWORK DESIGN: HOW IS IT DONE?
}

\author{
Judy Wynekoop \\ David Johnson \\ Florida Gulf Coast University \\ Fort Myers, Florida 33965 \\ U.S.A. \\ Jim Finan \\ JFC Systems \\ Estero, Florida 33928 \\ U.S.A.
}

\begin{abstract}
Networks, especially wide area networks, are increasingly important to organizations, yet network infrastructures may be flawed. This paper discusses what is known about how enterprise networks are designed, updated, and redesigned, drawing on experience and the literature. Research directions are proposed.
\end{abstract}

\section{INTRODUCTION}

Although recently much attention has been paid to the lack of knowledge about how information systems are actually developed and how system development methodologies are used or adapted (Wynekoop and Russo 1997), little attention has been given to how enterprise networks involving wide area networks (WANs) are actually designed (or redesigned) or to the methods used to do so. The enterprise network infrastructure is the backbone of a business: it must support existing and evolving applications, databases, and business goals reliably, and be adaptable and accessible. Organizations' infrastructure problems are now far greater than their applications development problems (Kern et al. 2000). This is especially important in view of the decentralization trends in today's organizations where the network must play a unifying and integrating role.

The original version of this chapter was revised: The copyright line was incorrect. This has been corrected. The Erratum to this chapter is available at DOI: 10.1007/978-0-387-35489-7_33 
The interdependence of the network infrastructure and business goals appears to be so self-evident that, as with systems development, scholars and practitioners seem to have assumed that network personnel follow sound methods for ensuring networks function reliably, support all business applications, and support business goals. Research and methods have concentrated on the endpoints - on the design of systems that provide information-not on how information is moved (Keen 1993). Since the movement of information is so critical, one would expect a great deal of attention to be paid to how the underlying networks are designed.

In the remainder of this paper, systems development and network design literature is briefly reviewed and brought to bear on the issue of designing and redesigning enterprise networks. We conclude with research issues.

\section{RELATED LITERATURE}

There has been no systematic study of how networks are developed (and little coverage in the trade press). It seems as though the research community has regarded wide area network infrastructures as a utility - much like streets or electricity. They exist in the background, someone else takes care of them, and users are inconvenienced when they are not functioning. Although this may be a natural outgrowth of the isolated evolution of the telecommunications function in businesses, it is not necessarily sound in today's decentralized and changing business environment (Segars and Grover 1994).

Since the network design process hasn't been studied, enterprise networks may routinely be designed and redesigned with little consultation with users, application developers, or business planners.

The design and management of enterprise networks is technologically complex, and it has been noted that few people are likely to understand even a single networked information system. Because of the complexity and enormity of the task, even fewer people would be able to study more than one such system, resulting in a poor understanding of what practices will reduce or eliminate design and implementation errors or allow networked systems to be designed to offset these errors (Schneider 1998).

\section{NETWORKING}

The network design literature is largely engineering-based. For example, Lin (1996) describes a methodology for the concurrent design of hardware and software for a networked application. Networks may be designed using genetic algorithms (Premkumar et al. 2000). However, the consideration of business strategy or accommodation of application and database location is not addressed. 
How do data communications texts address network design? Either enterprise network design is omitted (e.g., Panko 2001) or there is one chapter that addresses network analysis, design, and implementation, typically at a high level. LAN design is often fairly comprehensively covered in the chapters on LAN technology; WAN and enterprise network design are omitted or relegated to one of the last chapters. This is an important omission, since data moves differently on wide area networks than on local area networks.

What if the future uses of the network are not yet known? The answer seems to be "bandwidth over-provisioning." True, it is better to have too much capacity than not enough. However, WAN technology is expensive: if unnecessary leased lines or bandwidth is installed, this could be a costly mistake. Communications hardware and service costs have not dropped as rapidly as other hardware costs. And what if the network isn't over-engineered enough? It is becoming increasingly difficult to predict exactly what applications people will be running from minute to minute. If bandwidth is allocated by guesswork, it is possible that, although more than adequate bandwidth exists for routine operations, the network is inadequate at unpredicted times (Goldman 1998; Grigonis 2001). Although it is widely agreed that trying to forecast technology or business beyond three years is risky, does it make sense to develop a wide area network infrastructure independently of application or database design plans or business strategy, investing in capacity or technology that may never be needed or used?

Data communications texts do agree that networks must support existing and planned usage. Most address the importance of conducting a baseline study so that results can be used to identify the strengths and weaknesses of a network and then intelligently upgrade the network. Some mention the importance of conducting capacity planning studies to see if the network can handle proposed information systems. Virtually none address how this should be done. Apparently the "how" is left to systems development methodologies or processes. However, as noted below, systems development methodologies also reject responsibility.

Only one of the nine data communications texts we reviewed addressed network design and updating in detail (Goldman 1998), emphasizing that network design or redesign must be driven by the business goals and that a network should be designed or upgraded by understanding data attributes by examining the transactions that produce them, defining circuits based on bandwidth and delay requirements determined by the data and traffic analysis, and identifying networking devices to transport this data over the circuits to meet overall and local business needs. Goldman adds that this is rarely done in practice.

True, physical network design addresses the specification of switching elements and transmission elements. Telecommunications companies, both local and inter-exchange carriers, can physically design a network according to customer requirements. Traffic engineers can calculate the load on a circuit of 
a specific bandwidth. However, the estimated number of packets that will be sent over that circuit is an input to their calculations. IS professionals need the knowledge and methods to perform the analysis and logical design to provide information to traffic engineers and to understand if the resulting physical design will meet their business needs.

\section{SYSTEMS DEVELOPMENT METHODS}

Recently, with the increased importance of client-server networks and the Internet, systems development texts and research have addressed networked applications. However, methodologies and researchers seem to assume that the network to support the application exists or will be developed by someone else. Methodologies for developing web applications, network-based cooperative systems, and other distributed systems are discussed, but the existence of the underlying network topology, bandwidth, hardware, and other technologies is assumed. Sometimes reference is made to the need to call in technical data communications experts. Participatory design methods that have been applied to WANs have involved users determining the content and design of web pages, but an adequate network infrastructure is assumed to exist (Ellis et al. 1998).

Systems analysis and design texts do address tools and techniques for designing distributed systems. Location connectivity diagrams (LCD) are introduced as a tool to document the location of nodes in wide area and local area networks. For example, Whitten and Bentley (1998) stress that it is important to synchronize LCDs with data models in order to identify the locations of data and, more importantly, which entities and attributes various locations can create, read, delete, and update. The importance of synchronizing the process model and LCD is also emphasized: a process-to-location association matrix describes what processes are done at which locations, but it is assumed that an adequate network infrastructure exists.

\section{PRACTICE}

The trade press is silent on methods to develop enterprise networks. Although trade journals are replete with articles touting network monitoring, we could find no studies of how the information gained by monitoring a network is used to redesign the network.

Two comprehensive books on enterprise network design were located (Norris and Pretty 2000; Oppenheimer 1999). These books present analysis and design methods which, if followed, could lead to well-designed, robust, and adaptable networks. However, the use of these methods has not been studied. Our experience has shown that the design of a network seems to be related most 
to budget: networks are often "over-provisioned" to the extent the budget allows.

\section{DISCUSSION}

In summary, it appears that although an IS architecture driven by business strategies is lauded, enterprise network design is slighted or skipped in data communication texts, mirroring research and, in our experience, practice. Graduates from IS programs, therefore, have little or no understanding of WAN design or its dependence on business and IS planning. Processes and methods used to design enterprise networks have not been addressed in systematic research.

The goal of this paper is to raise questions about our knowledge of how complex wide area networks are developed and suggest research questions. Several questions flow directly from the preceding discussion.

1. Is there a problem? If there are no problems from poorly designed networks, there may be nothing to fix.

2. How are enterprise networks designed? Are any methods followed? How well do they work?

3. What is the role of management, business specialists, business planners, or network users in the assessment and redesign of networks?

4. Are enterprise networks designed and upgraded based on an organization's strategic plan?

5. In a merger or acquisition, how is the enterprise network infrastructure assessed and redesigned for the combined company?

Although not comprehensive, these questions highlight that studying how enterprise networks are designed and redesigned is key to understanding what academicians can contribute and to the informed development of computer-aided network engineering tools, which currently address technical issues involved with network design.

\section{RESEARCH DIRECTIONS}

We have reviewed data communications and software development texts. We are currently surveying IS curricula at North American universities to determine whether and how network design is taught. This will contribute to our understanding of what, if any, methodologies exist, and how they are transferred to practice.

We are reviewing IS implementation studies and cases of the past decade to identify instances where the network may have contributed to any problems or 
failures. We are looking for networked information systems that fail to meet user or organizational requirements, as well as indications of bandwidth or quality of service problems, resulting in poor response times or unpredictable network availability, and cost overruns from over-provisioning. Once the scope and nature of the problem is identified, a plan for field research can be developed.

We are also working on an IS maturity framework to use for the study of the development of enterprise networks and networked systems, expecting that more telecommunications technologies and methods are implemented in organizations with a mature IS function (Ellis et al. 1994). A mature organization would follow established procedures for involving other areas of IS, as well as network users, in network decisions. In a mature environment, service level agreements would exist, stating what users could expect from the network. A mature organization would not only gather baseline data for network performance, but also would routinely monitor the network and use the information to both tune the network and plan major upgrades. Immature communications functions would not collect or use ongoing metrics. Network changes would be made on the basis of "gut feeling" or the best the budget could support.

Thirty years ago programmers developed information systems the way they thought they should be developed - and many of these systems failed. That gave rise to efforts to improve the software development process and product, such as methodologies, participatory development, and the software process maturity model. However, until the last decade, little attention was paid to whether the methods were being used or how well they worked. Networked information systems today often fail and the reasons remain unknown (Schneider 1998). With the increasing importance of network infrastructures, it would seem to be time for an assessment of the state of network design to inform process improvement. As networks become increasingly important to organizations and society, it is critical that we understand how to design effective, reliable, efficient, and adaptable enterprise networks.

\section{REFERENCES}

Ellis, R. R., Jankowski, T. B., and Jasper, J. E. "Participatory Design of an Internet-Based Information System for Aging Services Professionals," The Gerontologist (38:6), 1998, pp. 743-748.

Ellis, R. W., Jones, M. C., and Arnett, K. P. "Local Area Network Adoption: An Empirical Assessment," Information Resources Management Journal (7:4), 1994, pp. 20-29.

Goldman, J. E. Applied Data Communications ( ${ }^{\text {nd }}$ Edition), New York: John Wiley \& Sons, 1998.

Grigonis, R. "Working the QoS Puzzle," Computer Telephony, January 2, 2001 (available from http://www.computertelephony.com/article/CTM20001221S0001, accessed February 26, 2001). 
Keen, P. G.W. "Information Technology and the Management Difference: A Fusion Map," IBM Systems Journal (32:1), 1993, pp. 17-39.

Kern, H., Galup, S. D., and Nemiro, G. IT Organization, Upper-Saddle River, NJ: Prentice Hall, 2000.

Lin, B. "A System Design Methodology for Software/Hardware Co-development of Telecommunication Network Applications," Thirty-third Design Automation Conference, New York: Association for Computing Machinery, 1996.

Norris, M., and Pretty, S. Designing the Total Area Network, Chichester, England: John Wiley \& Sons, 2000.

Oppenheimer, P. Top-Down Network Design, Indianapolis, IN: Macmillan, 1999.

Panko, R. R. Business Data Communications and Networking, Upper Saddle River, NJ: Prentice Hall, 2001.

Premkumar, G., Chu, C., and Chou, H. "Telecommunications Network Design: Comparison of Alternative Approaches," Decision Sciences Journal (31:2), 2000, pp. 483-506.

Schneider, F. B. "Toward Trustworthy Networked Information Systems," Communications of the $\operatorname{ACM}(40: 11), 1998$, p. 144.

Segars, A. H., and Grover, V. "Communications Architecture: Towards a More Robust Understanding of Information Flows and Emergent Patterns of Communication in Organizations," European Journal of Information Systems (3:2), 1994, pp. 87-100.

Whitten, J. L., and Bentley, L. D. Analysis and Design Methods, New York: Irwin/McGraw-Hill, 1998.

Wynekoop, J. L., and Russo, N. L. "Studying Systems Development Methodologies: An Examination of Research Methods," Information Systems Journal (7), 1997, pp. 47-65.

\section{About the Authors}

Judy Wynekoop is an asociate pofessor of Computer Information Systems at Florida Gulf Coast University, with a Ph.D. in Information Systems, Georgia State University (1991). She teaches courses in data communications, network design, and eBusiness infrastructures. Her research focuses on the attributes, behaviors, and performance of individuals and groups in the development and deployment of information technology. Judy can be reached by e-mail at jwynekoo@fgcu.edu.

David Johnson is a visiting professor of Computer Information Systems at Florida Gulf Coast University, with a Ph.D. in Computer Information Systems, University of Michigan (1981). He has 25 years of industry experience in information systems development. Special interests include strategic information technology planning, information systems analysis and design, database management, and application development. David can be reached by e-mail at djohnson@fgcu.edu.

Jim Finan is vice president and general manager of JFC Systems. He has worked as a systems integrator and network consultant for 10 years, specializing in small business networks and Unix systems. Jim can be reached by e-mail at jimfinan@worldnet.att.net. 